\title{
Spatial ecology of Carcharias taurus in the northwestern Mid-Atlantic coastal ocean
}

\author{
D. E. Haulsee ${ }^{1, *}$, M. W. Breece ${ }^{1}$, L. M. Brown ${ }^{2}$, B. M. Wetherbee ${ }^{3}$, D. A. Fox ${ }^{2}$, \\ M. J. Oliver ${ }^{1}$ \\ ${ }^{1}$ College of Earth, Ocean and the Environment, University of Delaware, Lewes, DE 19958, USA \\ ${ }^{2}$ Department of Agriculture and Natural Resources, Delaware State University, Dover, DE 19901, USA \\ ${ }^{3}$ Department of Biological Sciences, University of Rhode Island, Kingston, RI 02811, USA
}

\begin{abstract}
The sand tiger shark Carcharias taurus is a highly migratory coastal species with declining populations worldwide. This species exhibits many behaviors that make coastal sharks difficult to manage, including aggregatory behavior, sexual segregation, and large-scale migrations through shallow coastal waters with many opportunities for human interactions. Sand tigers from the Western North Atlantic subpopulation are known to seasonally inhabit Delaware Bay and surrounding coastal waters. This region has been recommended as a habitat area of particular concern for the Western North Atlantic sand tiger population, and increased understanding of their movements and habitat requirements will facilitate management efforts. We developed models to predict sand tiger occupancy using spatially dynamic environmental predictors. Our models predicted sand tiger (juveniles, adult males, adult females, and all sharks combined) occurrences in 2 study regions, the Delaware Bay and the western Mid-Atlantic coastal ocean. Sea surface temperature, day of year, water depth, and remote sensing reflectance at $555 \mathrm{~nm}$ were the most important environmental predictors of occurrence, and correctly predicted $80-89 \%$ of sand tiger acoustic telemetry records in the 2 study regions. Our models predicted differences in the timing and location of occurrences among juveniles and adults, as well as areas where these life history stages overlap in the Mid-Atlantic coastal ocean. Our hope is that a daily forecast of sand tiger occurrence from our modeling efforts could be useful for conservation and management efforts in this important region, as well as for studying the spatial and behavioral ecology of this important top predator.
\end{abstract}

KEY WORDS: Acoustic telemetry - Generalized additive mixed model - Predictive habitat modeling $\cdot$ Species distribution $\cdot$ Sand tiger shark $\cdot$ Carcharias taurus

\section{INTRODUCTION}

The removal of sharks from the ocean negatively affects the health of the ecosystems, as these top predators serve an important role in structuring the food web through consumptive and non-consumptive effects (Stevens et al. 2000, Myers \& Worm 2003, Burkholder et al. 2013, Bornatowski et al. 2014). For these reasons, there is much concern about declining shark populations worldwide, and managers are making efforts to enact meaningful conservation and management strategies to reverse these trends

\footnotetext{
${ }^{*}$ Corresponding author: dhaulsee@udel.edu
}

(Topelko \& Dearden 2005, Kinney \& Simpfendorfer 2009). Many sharks, especially those that inhabit the coastal ocean, face direct anthropogenic threats such as habitat degradation and fishing pressures (Speed et al. 2010, Kneebone et al. 2013, Kilfoil et al. 2017). The majority of temperate coastal sharks undergo large-scale seasonal migrations, traversing political boundaries, and necessitating coordination among managing organizations to effectively manage the entire population (Musick et al. 2000, Speed et al. 2010). Furthermore, many coastal sharks segregate by life history stage (Simpfendorfer et al. 2005, Sims

(C) The authors 2018. Open Access under Creative Commons by Attribution Licence. Use, distribution and reproduction are unrestricted. Authors and original publication must be credited. 
2005, Speed et al. 2010, Bansemer \& Bennett 2011, Haulsee et al. 2016), which can result in segments of the population being disproportionally affected by disturbances and/or protective measures.

Passive acoustic telemetry is commonly used to monitor the movements and migrations of marine animals (Heupel et al. 2006, Donaldson et al. 2014, Hussey et al. 2015). This technique allows researchers to monitor numerous individuals of species large enough to carry a transmitter into the detection range of moored acoustic receiving arrays (Jackson 2011, Kneebone et al. 2012, Haulsee et al. 2015). To understand how these movements are related to the environment, locations from acoustic telemetry need to be appropriately matched to environmental predictors. Environmental sensors, such as those aboard the MODIS-Aqua, collect measurements such as sea surface temperature (SST) and ocean color at scales relevant for dynamic broadscale species distribution models (Breece et al. 2016, Scales et al. 2017). Ocean temperature often relates to a species distribution exhibited by marine organisms due to physiological constraints (Manderson 2016), and water color properties are often considered proxies for in situ properties such as turbidity, salinity, and chlorophyll a concentrations, an indicator of primary productivity (Siegel et al. 2005, Geiger et al. 2013). Even though remotely sensed temperature and color are measured on the surface of the ocean, a growing number of studies have documented their value in predicting marine species distributions (Adams et al. 2016, Breece et al. 2016, Hazen et al. 2017).

The sand tiger Carcharias taurus is a large coastal shark with discrete sub-populations found in subtropical-temperate coastal waters around the world (Ahonen et al. 2009). Their low productivity, slow growth, and aggregatory behavior has put sand tigers at risk from recreational fishing and as bycatch in commercial fisheries, and they have been identified as highly prone to extinction (García et al. 2008). Sand tigers have experienced population declines worldwide and are listed as 'Vulnerable' (Pollard \& Smith 2009) and 'Critically Endangered' in 2 subpopulations by the IUCN (Eastern Australia: Pollard et al. 2003 and Southwest Atlantic: Chiaramonte et al. 2007). Sand tigers are listed as a 'species of concern' by the National Oceanic and Atmospheric Administration (NOAA) (Carlson et al. 2009), and NOAA is considering designating Delaware Bay, USA, as a 'habitat area of particular concern' in an effort to work towards recovery of the stock (NOAA 2017).
Sand tigers have been documented making seasonal migrations in the coastal ocean in all of their major populations (i.e. Northwest Atlantic: Kneebone et al. 2014, Teter et al. 2015, Haulsee et al. 2016; Southwest Atlantic: Lucifora et al. 2002; South Africa: Dicken et al. 2007; and eastern Australia: Bansemer \& Bennett 2011), which are thought to be related to their reproduction and seasonal habitat suitability. In the Northwest Atlantic Ocean, sand tigers are often found aggregating in schools (Compagno 2001, Carlson et al. 2009). Adults and juveniles frequent the Delaware Bay and the surrounding coastal ocean from the early spring to the late fall (Compagno 2001, Kilfoil 2017 , Haulsee et al. 2015, 2016). The range of juveniles appears to extend much further north along the US east coast than the range of adults, but the reason for this difference in range is unknown (Kneebone et al. 2014). In addition, there is also evidence for sexually segregated migration patterns in adult sand tigers during the fall off of the Mid-Atlantic coast, with some adult females using waters further offshore than the rest of the population (Teter et al. 2015). It is hypothesized that mating and pupping occur in coastal waters off the southeastern US, but to our knowledge it remains unclear where and when these behaviors occur. Both juveniles and adults have been observed as far south as the coastal waters off Florida, USA (Kneebone et al. 2014 and D. Fox unpubl. data). The environmental conditions driving sand tiger distribution along the US east coast are poorly understood, and estimating the utility of such conditions to predict their occurrence may help towards explaining their distribution and migratory behavior.

We used passive acoustic telemetry and remotely sensed ocean surface measurements to spatially resolve the migration and habitat use of sand tigers in the western Mid-Atlantic coastal ocean (Mid-Atlantic Bight). Our models create spatially explicit age- and sex-based occurrence predictions, and reveal seasonally distinct migratory corridors. These predictive models can be incorporated into real-time spatial data streams for use by managers working to conserve this species of concern.

\section{MATERIALS AND METHODS}

\section{Location record collection}

Sand tiger location records were obtained using passive acoustic telemetry. This study leveraged tagging efforts for projects carried out by Delaware State University and the University of Delaware be- 
tween 2007 and 2013 (Haulsee et al. 2015, 2016, Kilfoil et al. 2017). During that time, 303 sand tigers were captured and tagged with acoustic transmitters (V16-6H, n = 207; V16P-6H, n = 43; V16-5H, external, $\mathrm{n}=33$; VMT-1H/V16-4H dual tagged, $\mathrm{n}=20$; VEMCO) in the Delaware Bay and surrounding Delaware coastal waters in accordance with the Delaware Department of Natural Resources and Environmental Control (DNREC; 2012-021F), Delaware State University Institutional Animal Care and Use Committee (IACUC) and the University of Delaware IACUC (1259-2014-0). Battery life of transmitters deployed ranged from 4-10 yr, allowing us to monitor individual sand tigers for multiple years. Most transmitters were internally implanted into the coelomic cavity unless otherwise noted in the initial study publication (see Haulsee et al. 2015, 2016, Kilfoil et al. 2017 for tag implantation methodology). Acoustic transmitter pulse rates varied between 10 and 190 s. Sex, fork length, and total length (TL) were documented for each sand tiger.

Acoustic transmitters were recorded on VR2 and VR2W (VEMCO) passive acoustic receivers deployed in the Delaware Bay and nearby coastal ocean in waters up to $25 \mathrm{~m}$ deep (Fig. 1). For logistical reasons, the entire acoustic array was not deployed year-round; however, during most years, receivers in the coastal ocean were present during all seasons. We were unable to estimate the detection ranges for the receivers in this array, but previous studies have estimated the detection range of VR2 and VR2W acoustic receivers to be at most $1.4 \mathrm{~km}$, and average detection ranges are usually <600 m (Kessel et al. 2014, Haulsee et al. 2015, Kilfoil et al. 2017, Oliver et al. 2017). These detection range estimates are consistent with the spatial grain of our model projections (see below). Acoustic receiver detection range can vary over time depending on conditions and transmitter power, which could result in an underestimation of sand tiger presence. The acoustic records were manually filtered to remove tags that remained on a single receiver continuously for multiple seasons (likely dropped tags, extruded tags, or a sand tiger that perished) or to remove detections that were likely caused by code collision (e.g. single detections).

\section{Model data preparation}

Our study focuses on detections of sand tigers between 16 May 2009 and 31 August 2013. Individual sand tiger occurrences on acoustic receivers were treated as daily events at each location. A sand tiger

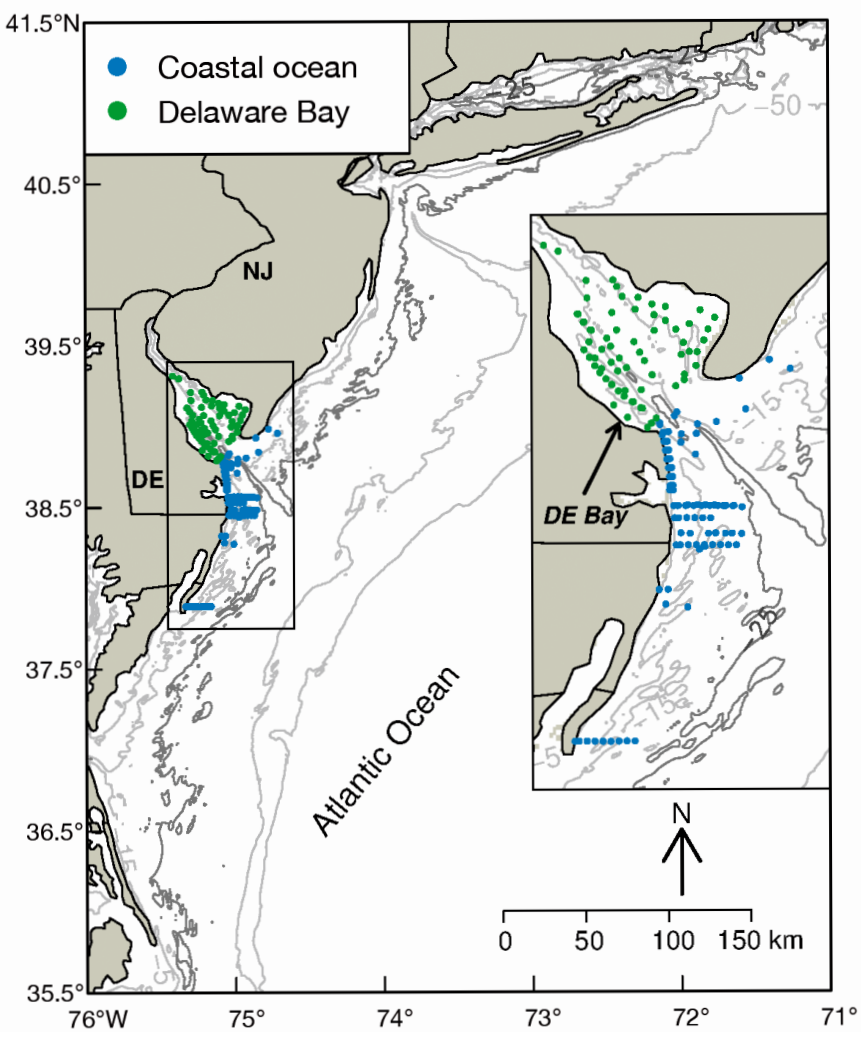

Fig. 1. Study domain in the western mid-Atlantic coastal ocean off the USA east coast. Colored points represent the positions of VEMCO VR2W moored receiving stations deployed between 2009 and 2013. Detection records recorded by these receivers provided presences and absences of acoustically tagged sand tiger sharks Carcharias taurus

could therefore be present on multiple receivers in various environmental conditions each day, but each receiver was only counted as a presence once per day to eliminate auto-correlation. The time between the date of transmitter deployment and the last date of detection of that transmitter was considered the time interval where the individual could be counted as present or absent. Each receiver station where a transmitter was not detected in this time interval was considered an absence for that individual.

\section{Predictor variables}

Sand tiger presences and absences were matched to daily, $1 \mathrm{~km}^{2}$ sea surface environmental conditions measured by the MODIS-Aqua satellite sensor. Daily level 2 MODIS-Aqua data were retrieved from the NASA Ocean Color Biology Processing Group, processed to $1 \mathrm{~km}^{2}$ resolution, and were aggregated here (http://basin.ceoe.udel.edu/thredds/dodsC/Aqua1 DayAggregate.nc.html) as part of the Mid-Atlantic 
Regional Association Coastal Ocean Observing System (MARACOOS). Remote sensing data were spatially restricted to the Mid-Atlantic coastal ocean between coastal Rhode Island and Cape Hatteras, North Carolina, which is the approximate extent of MARACOOS. In total, 30 sea surface satellite products were matched to sand tiger presences and absences (see Figs. S1 \& S2 and Table S1 in Supplement 1 at www. int-res.com/articles/suppl/m597p191_supp.pdf). The water depth at each receiver station was extracted from a high-resolution bathymetry map (1 arc-second, NOAA National Centers for Environmental Information, U.S. coastal relief model). We also included day of year as a potential predictor variable to account for seasonality and migration cues not captured by the satellite-measured environmental datasets.

To reduce the number of predictor variables included in the habitat model, we computed the information value scores for each predictor using the create infotables function in the $\mathrm{R}$ statistical enviroment (InformationValue; Prabhakaran 2016, R Core Team 2017). For predictor variables that were correlated $(|r|>$ $0.70)$, the predictor variable with the highest information value was selected for model testing (Wegmann et al. 2016). In addition, the availability of predictor variables on future satellite observation platforms was also considered as a factor for predictor suitability.

\section{Model design and selection}

To model the non-linear relationship between sand tiger occurrence and the environment, we used generalized additive mixed models (GAMMs; Lin \& Zhang 1999). Similar to generalized additive models (Hastie \& Tibshirani 1990), this modeling technique estimates the complex relationships between predictor (e.g. remotely sensed environmental variables) and binomial response (e.g. presence/absence of sand tigers) variables, but allows for the interaction of a random effect (e.g. individual sand tiger behavior; Wood 2004, 2006, Aarts et al. 2008, Manderson et al. 2014). GAMMs were fit using the 'gamm4' package (Wood \& Scheipl 2016) in the R statistical environment. Thin plate penalized shrinkage smoothers (ts) were used to model the relationship between fixed environmental effects and the binomial response (presence/ absence) of sand tigers. Specifying a maximum of 6 knots (representing the maximum number of inflections in fitted models), we limited smoothers to a maximum of 5 effective degrees of freedom to reduce model over-fitting and complexity (Wegmann et al. 2016). The use of shrinkage smoothers penalizes the degrees of freedom of smoothed covariates that do not contribute to model performance (Marra \& Wood 2011). Tensor product smooths (t2) were used to test 2 -way interactions between different combinations of environmental variables (Wood et al. 2013).

Preliminary data exploration and observations in the field suggested that the relationship between sand tiger presence and their environment differed depending on whether they were inside or outside of Delaware Bay. In addition, changes in the behavior of the animals (i.e. migrations in the coastal ocean vs. over-summering in Delaware Bay, Haulsee et al. 2016), led to differences in habitat use. Because of these reasons, we chose to build separate models for sharks inside and outside of Delaware Bay. To test for potential behavioral response differences among the different life history stages as observed in other shark species (Sims 2005, Mucientes et al. 2009), we also built separate models inside and outside of the bay based on the size (at time of tagging) and sex. Males <190 cm TL and females <220 cm TL were considered juveniles (Gilmore et al. 1983). Preliminary data exploration showed no difference in the behavior between male and female juveniles, and therefore they were combined.

We systematically tested for effects of interactions with the selected environmental predictors using reduction of Akaike's information criterion (AIC) as an indicator of increased model performance (Wood 2006). Including too many interaction terms can prevent models from converging, or can cause models to become so complex that they are no longer interpretable. Keeping this in mind, we selected models that had reduced AIC scores, but were still ecologically interpretable and were the least complex.

To calculate how much the predictor variables were contributing to the overall performance of our top models, we used the 'varImpBiomod' function in R (source code available here: https://bitbucket.org/ rsbiodiv/species_distribution_model/src, Wegmann et al. 2016). This function returns the variable importance score for each predictor variable in the final top models by systematically pulling out and randomizing each variable, and then correlating the prediction made after randomization to the prediction made by the original model (Wegmann et al. 2016).

To test for potential model over-fitting, we ran a 5fold cross validation of our top selected models (Wegmann et al. 2016). Over 5 iterations, the top models were re-trained on $80 \%$ of the data, reserving $20 \%$ of the data to use for prediction using the newly created model parameters. From this cross validation, a probability of occurrence was predicted for every 
presence and absence observation, allowing us to calculate the explained deviance $\left(\mathrm{r}^{2}\right)$, sensitivity (presences correctly predicted), specificity (absences correctly predicted), optimal threshold (predicted prevalence where sensitivity equals specificity), percent correctly classified (PCC), and the area under the receiver operating curve (AUC), using the 'Presence Absence' package in R (Freeman 2008).

\section{Model visualizations}

Relative probability of occurrence maps were created by inputting historic $1 \mathrm{~km}^{2}$ satellite layers from NASA's MODIS-aqua satellite freely available online (http://basin.ceoe.udel.edu/thredds/catalog.html) into the best performing models in R. Coastal ocean models were used to model sand tiger occurrence in the broader Mid-Atlantic coastal ocean, while the Delaware Bay models were used to model their occurrence within the confines of the Delaware Bay. For static visualizations, we used $8 \mathrm{~d}$ climatologies of satellite predictor variables from 2002-2016 to create probability of occurrence maps based on the average conditions. Input datasets were constrained to only include data values within the ranges of the matched predictor variables to avoid extrapolation of model predictions into novel conditions.

\section{Ecological overlap}

We visualized areas of overlap between adults and juveniles using the top models created for each subgroup inside of the Delaware Bay and in the coastal ocean model domains. Occurrences of adults (males and females combined for visualization simplicity) and juveniles (males and females combined) were predicted using the top models for each sub-group and the $8 \mathrm{~d}$ climatologies of satellite predictor variables as inputs. Predicted probability of occurrence levels above the optimal threshold for each subgroup were considered a presence for that subgroup, and predicted probability of occurrence below the threshold was considered an absence.

\section{RESULTS}

\section{Sand tiger detections}

Between 16 May 2009 and 31 August 2013, we recorded 52674 daily detection events for 264 of the
303 acoustically tagged sand tigers in the Delaware Bay and the coastal ocean VR2W acoustic receiver arrays (Fig. 1). Of these detections, $17 \%$ (8776) were matched to $1 \mathrm{~d}$ environmental predictor variables measured by satellite due to missing data in the satellite record (i.e. clouds). This dataset was derived from 109 juveniles (34 males, 75 females), 102 adult males, and 45 adult females. The Delaware Bay study region contained more receivers than the coastal ocean study region, and therefore also recorded more matched acoustic detections of sand tigers (8211 vs. 565). During this time, there were 6481980 absences, or cumulative days when receivers and transmitters were both active for all transmitters combined; however, only 1295315 ( 20\%) of those absences could be matched to satellite-measured environmental variables. Large sample sizes can substantially increase machine time and also prevent model convergence (Wood et al. 2013), thus we randomly sub-sampled $5 \%$ (64766) of the absences for GAMM input. The number of presences and absences per individual contributing to each model varied (see Fig. S3 in Supplement 1).

\section{Environmental predictors and model selection}

Analysis of the information valuation and correlation among environmental predictor variables reduced the number of variables for model testing from 30 to 4 . In the coastal ocean, the top model for juveniles, adult males, and all sharks combined included combinations of day of year (DOY), SST, water depth, and remote sensing reflectance at $555 \mathrm{~nm}\left(\mathrm{R}_{\mathrm{r} 5555}\right.$ Table 1, and see Table S2 in Supplement 1). The top model for adult females in the coastal ocean included SST, DOY, and $\mathrm{R}_{\mathrm{rs} 555}$ (Table 1; see Table $\mathrm{S} 2$ ). In the Delaware Bay study region, the top models included combinations of depth, SST, and DOY (Table 1; see Table S3).

Environmental conditions where sand tigers were present differed between the coastal ocean and Delaware Bay and also by life history stage (Table 2). Generally, the mean depth where sand tigers were recorded appears shallower in the Delaware Bay than in the coastal ocean (Table 2). Sand tigers were found in colder surface water temperatures in the coastal ocean than in the Delaware Bay (Table 2). Juveniles consistently arrived earlier to the coastal ocean and Delaware Bay study regions (Fig. 2) and were found in cooler SSTs than adult males and females, although the average SSTs were similar among life history stages (Table 2). In the coastal 
Table 1. Top performing generalized additive mixed model summaries for models predicting sand tiger Carcharias taurus occurrence in the coastal ocean and Delaware Bay study regions. edf: estimated degrees of freedom; PCC: percent correctly classified; Sens.: sensitivity (percent presences correctly predicted); Spec.: specificity (percent absences correctly predicted); AUC: area under the receiver operating curve; s: thin plate regression spline smoother; $\mathrm{t} 2$ : tensor product smoother; SST: sea surface temperature; DOY: day of year; $\mathrm{R}_{\mathrm{rs} 555}$ : remote sensing reflectance at $555 \mathrm{~nm}$. All variables are significant at $\mathrm{p}<0.001$

\begin{tabular}{|c|c|c|c|c|c|c|c|}
\hline Predictor variables & edf & Threshold & PCC & Sens. & Spec. & AUC & $\mathrm{r}^{2}$ \\
\hline \multicolumn{8}{|l|}{ Coastal ocean } \\
\hline All & & 0.02 & 0.88 & 0.87 & 0.88 & 0.95 & 0.42 \\
\hline s(Depth) & 4.88 & & & & & & \\
\hline $\mathrm{s}\left(\mathrm{R}_{\mathrm{rs} 555}\right)$ & 4.10 & & & & & & \\
\hline t2(SST, DOY) & 18.02 & & & & & & \\
\hline & 0.03 & 0.89 & 0.87 & 0.89 & 0.95 & 0.42 \\
\hline s(Depth) & 4.85 & & & & & & \\
\hline $\mathrm{s}\left(\mathrm{R}_{\mathrm{rs} 555}\right)$ & 4.02 & & & & & & \\
\hline t2(SST, DOY) & 12.94 & & & & & & \\
\hline & 0.02 & 0.86 & 0.83 & 0.86 & 0.93 & 0.36 \\
\hline $\mathrm{s}\left(\mathrm{R}_{\mathrm{rs} 555}\right)$ & 3.01 & & & & & & \\
\hline t2(SST, DOY) & 5.74 & & & & & & \\
\hline \multirow{4}{*}{$\begin{array}{l}\text { Juveniles } \\
\text { s(Depth) } \\
\left.\text { s(R } \text { R }_{\text {rs555 }}\right) \\
\text { t2(SST, DOY) }\end{array}$} & & 0.01 & 0.85 & 0.90 & 0.85 & 0.96 & 0.46 \\
\hline & 4.58 & & & & & & \\
\hline & 3.09 & & & & & & \\
\hline & 15.38 & & & & & & \\
\hline \multicolumn{8}{|l|}{ Delaware Bay } \\
\hline \multicolumn{2}{|l|}{ All } & 0.25 & 0.81 & 0.81 & 0.81 & 0.89 & 0.49 \\
\hline $\mathrm{s}(\mathrm{DOY})$ & 4.77 & & & & & & \\
\hline t2(SST, Depth) & 24.58 & & & & & & \\
\hline \multicolumn{2}{|l|}{ Adult males } & 0.25 & 082 & 0.83 & 0.82 & 0.90 & 0.51 \\
\hline $\mathrm{s}(\mathrm{DOY})$ & 4.71 & & & & & & \\
\hline t2(SST, Depth) & 16.51 & & & & & & \\
\hline \multirow{3}{*}{$\begin{array}{l}\text { Adult females } \\
\text { s(DOY) } \\
\text { t2(SST, Depth) }\end{array}$} & & 0.24 & 0.80 & 0.80 & 0.80 & 0.86 & 0.41 \\
\hline & 4.12 & & & & & & \\
\hline & 13.99 & & & & & & \\
\hline \multirow{3}{*}{$\begin{array}{l}\text { Juveniles } \\
\text { s(DOY) } \\
\text { t2(SST, Depth) }\end{array}$} & & 0.25 & 0.81 & 0.80 & 0.81 & 0.89 & 0.47 \\
\hline & 4.82 & & & & & & \\
\hline & 23.11 & & & & & & \\
\hline
\end{tabular}

\section{Coastal ocean model results}

In the coastal ocean study region, the response curves for depth in models of all sharks, adult males, and juveniles were generally bimodal, with peaks in positive response occurring at $\sim 12$ and $\sim 23 \mathrm{~m}$ depth for adult males, and at $\sim 10$ and $21 \mathrm{~m}$ for juveniles (Fig. 3). Patterns in sand tiger response to $\mathrm{R}_{\mathrm{rs} 555}$ were also generally similar among the 4 top models, with a positive model response in waters with $\mathrm{R}_{\mathrm{rs555}}$ measurements $>0.005 \mathrm{sr}^{-1}$ and high uncertainty in waters with the highest $\mathrm{R}_{\text {rs555 }}$ values (Fig. 3). The relationships between SST and DOY for all models were generally similar, with positive model responses regardless of SST between DOY 100 and 300 (April-October, Fig. 3). The adult female model had a negative response of shark occurrence before DOY $\sim 100$ and after DOY 300 regardless of SST (Fig. 3). The all-sharks, juvenile, and adult male models had a negative response of shark occurrence before DOY $\sim 100$ and after DOY $\sim 300$ if the SST was less than $\sim 20^{\circ} \mathrm{C}$, but had a positive response during that time if SST was greater than $\sim 20^{\circ} \mathrm{C}$ (Fig. 3).

\section{Delaware Bay model results}

In Delaware Bay, a positive model response was shifted $\sim 50$ d later in the spring compared to the coastal ocean (May-June), but was similar in the fall, with the negative model response obocean study region, $\mathrm{R}_{\mathrm{rs} 555}$ varied little among life history stages (Table 2).

Trends in variable importance were similar for each model in the coastal ocean study region, with the exception of adult females (see Fig. S4a in Supplement 1). SST and DOY contributed the most to all models except for adult females (see Fig. S4a in Supplement 1) where DOY and $\mathrm{R}_{\mathrm{rs} 555}$ were most important. In the Delaware Bay, DOY was the most important predictor variable for models of all sharks, adult females, and juveniles, followed by depth and SST (see Fig. S4b in Supplement 1). The adult male model differed, with depth and DOY contributing similarly to the model, followed by SST (see Fig. S4b in Supplement 1). served on DOY 300 (Fig. 4), which corresponds to patterns observed in Fig. 2. The interaction between SST and depth is complex for these models, but in general, waters warmer than around $15^{\circ} \mathrm{C}$ were predictive of sand tigers (Fig. 4). For all sharks combined, there was an avoidance of cooler deep waters (Fig. 4a), although this may have been influenced by the strong avoidance of cool deep waters by juveniles (Fig. 4d), as the adult male and female models show an avoidance of cool shallow waters in the bay (Fig. 4b,c). A positive response for the adult male and adult female models occurred in the deepest waters when SST was $\sim 15-18^{\circ} \mathrm{C}$, or in a bi-modal distribution at the shallowest depths and water $\sim 18-20 \mathrm{~m}$ when the SST was highest (Fig. 4b,c). 
Table 2. Summary statistics for environmental predictor variables associated with sand tiger Carcharias taurus presence in the coastal ocean and Delaware Bay study regions. SST: sea surface temperature, DOY: day of year, $\mathrm{R}_{\mathrm{rs} 555}$ : remote sensing reflectance at $555 \mathrm{~nm}$

\begin{tabular}{|c|c|c|c|c|}
\hline \multirow{2}{*}{$\begin{array}{l}\text { Predictor } \\
\text { variable }\end{array}$} & \multicolumn{2}{|c|}{ Coastal ocean } & \multicolumn{2}{|c|}{ Delaware Bay } \\
\hline & Range & Mean & Range & Mean \\
\hline \multicolumn{5}{|l|}{ All } \\
\hline Depth (m) & $5.70-24.40$ & 16.42 & $1.90-20.30$ & 8.03 \\
\hline $\operatorname{SST}\left({ }^{\circ} \mathrm{C}\right)$ & $13.26-26.64$ & 20.32 & $12.89-30.83$ & 24.96 \\
\hline DOY & $120-295$ & 261 & $115-294$ & 222 \\
\hline $\mathrm{R}_{\mathrm{rs} 555}\left(\mathrm{sr}^{-1}\right)$ & $0.002-0.014$ & 0.007 & - & - \\
\hline \multicolumn{5}{|l|}{ Adult males } \\
\hline Depth (m) & $5.70-24.40$ & 16.69 & $1.90-20.30$ & 8.15 \\
\hline $\operatorname{SST}\left({ }^{\circ} \mathrm{C}\right)$ & $16.99-26.64$ & 21.30 & $17.07-30.83$ & 25.15 \\
\hline DOY & $150-290$ & 256 & $151-289$ & 220 \\
\hline $\mathrm{R}_{\mathrm{rs} 555}\left(\mathrm{sr}^{-1}\right)$ & $0.002-0.013$ & 0.006 & - & - \\
\hline \multicolumn{5}{|c|}{ Adult females } \\
\hline Depth (m) & $5.70-24.40$ & 16.46 & $1.90-20.30$ & 7.94 \\
\hline $\operatorname{SST}\left({ }^{\circ} \mathrm{C}\right)$ & $15.77-25.38$ & 20.29 & $16.36-30.83$ & 24.56 \\
\hline DOY & 145-290 & 267 & $154-294$ & 228 \\
\hline $\mathrm{R}_{\mathrm{rs} 555}\left(\mathrm{sr}^{-1}\right)$ & $0.002-0.014$ & 0.007 & - & - \\
\hline \multicolumn{5}{|l|}{ Juveniles } \\
\hline Depth (m) & $8.90-24.40$ & 16.09 & $1.90-20.30$ & 7.95 \\
\hline $\operatorname{SST}\left({ }^{\circ} \mathrm{C}\right)$ & $13.63-25.68$ & 19.32 & $12.89-30.83$ & 24.86 \\
\hline DOY & 120-295 & 264 & 115-290 & 221 \\
\hline $\mathrm{R}_{\mathrm{rs} 55} 5\left(\mathrm{sr}^{-1}\right)$ & $0.002-0.014$ & 0.007 & - & - \\
\hline
\end{tabular}

\section{Model validation}

Cross-validation confirmed that our models performed well and were not over-fit. In the coastal ocean models, sensitivity scores ranged from 0.830.90, and specificity scores ranged from 0.85-0.89, indicating that these models are correctly predicting presences and absences of sand tigers $87 \%$ (average PCC across all models) of the time in the coastal study domain (Table 1). In the Delaware Bay models, sensitivity and specificity were slightly lower (0.800.83 and $0.80-0.82$, respectively), with an average PCC of $81 \%$ (Table 1).

\section{Spatial distribution and habitat overlap}

The top models for all life history subgroups and all sharks combined in each study region were used to create prediction maps of the probability of occurrence. Daily satellite imagery or climatologies were used for model projection. These outputs show dynamic patterns in potential sand tiger use of the MidAtlantic coastal ocean and Delaware Bay study regions (see Supplemental Movies 1-4 at www.int-res. com/articles/suppl/m597p191_supp/ as examples).

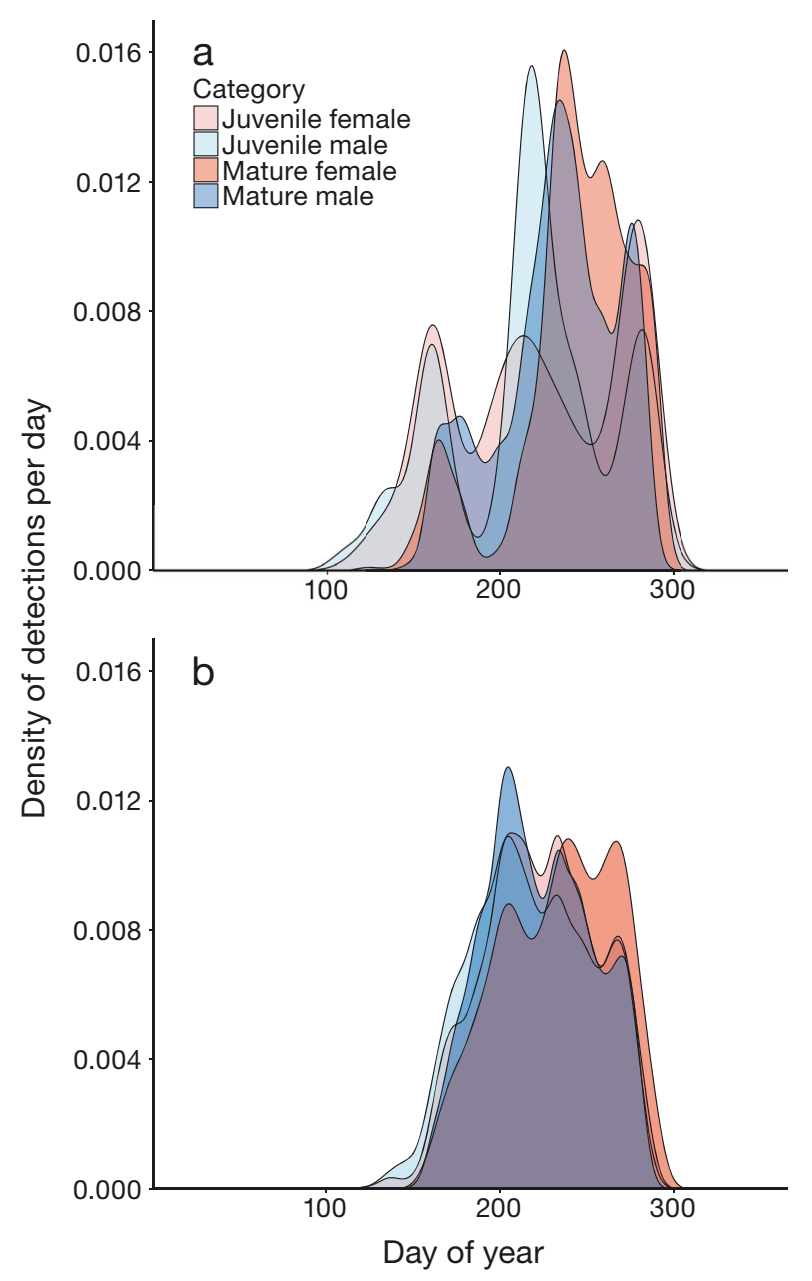

Fig. 2. Density of sand tiger Carcharias taurus presences recorded by VEMCO VR2W moored acoustic receivers in (a) the coastal ocean and (b) the Delaware Bay study regions for 2009-2013

All of the models predicted zero probability of occurrence in the winter months (Figs. 5a \& 6a, see Figs. S5a-S10a in Supplement 1).

Model predictions showed that sand tigers arrive in the coastal ocean in early May, with highest occurrences in the shallow, nearshore waters (Fig. 5b). However, most of these early arrivals appear to be juveniles (Figs. S5b-S7b). Following the juveniles, adults also appear to migrate into the coastal ocean study region using a narrow band of shallow nearshore water (Supplemental Movies 1-4). Sand tigers then enter Delaware Bay in early June (DOY 150), with some avoidance of the main channel and shallow sand flats (Fig. 6b).

By August (DOY 215), sand tigers were using shallow nearshore waters (Fig. 5c), and the shallowest and deepest parts of Delaware Bay (Fig. 6c). Juveniles and adult females had lower probabilities of occur- 
a)

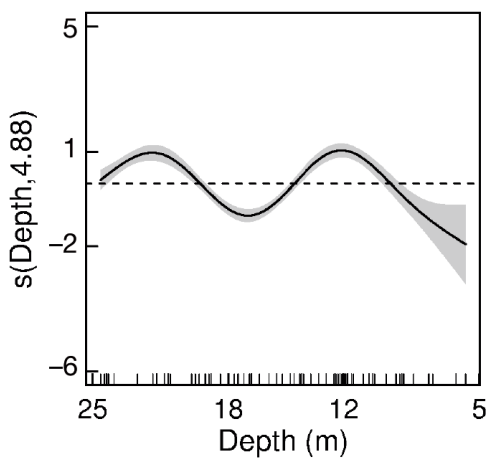

b)

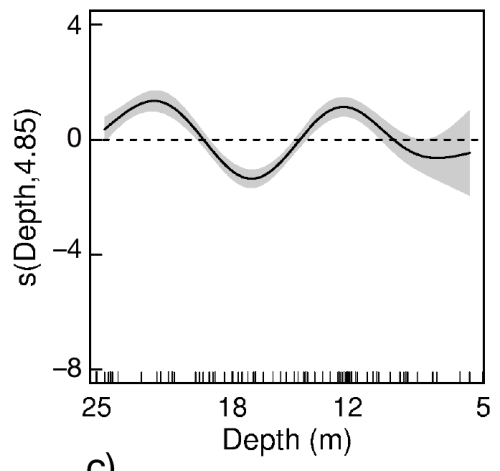

c)

d)

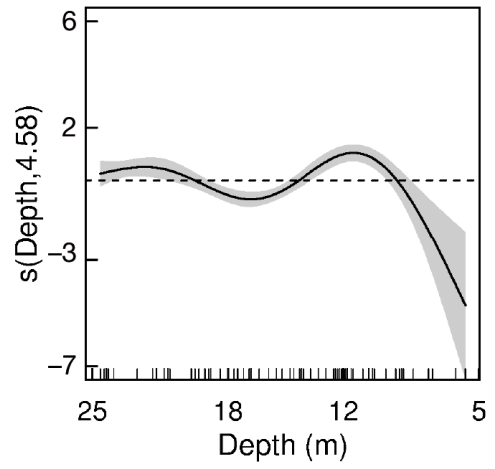

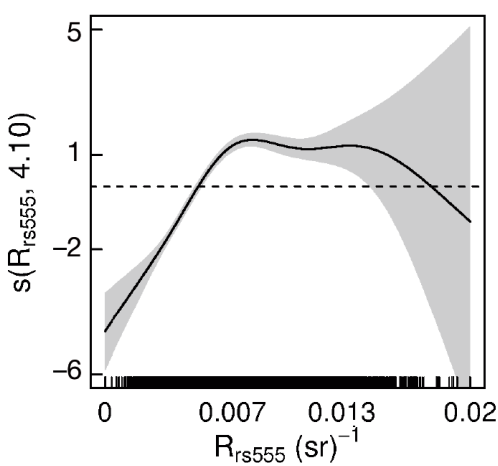
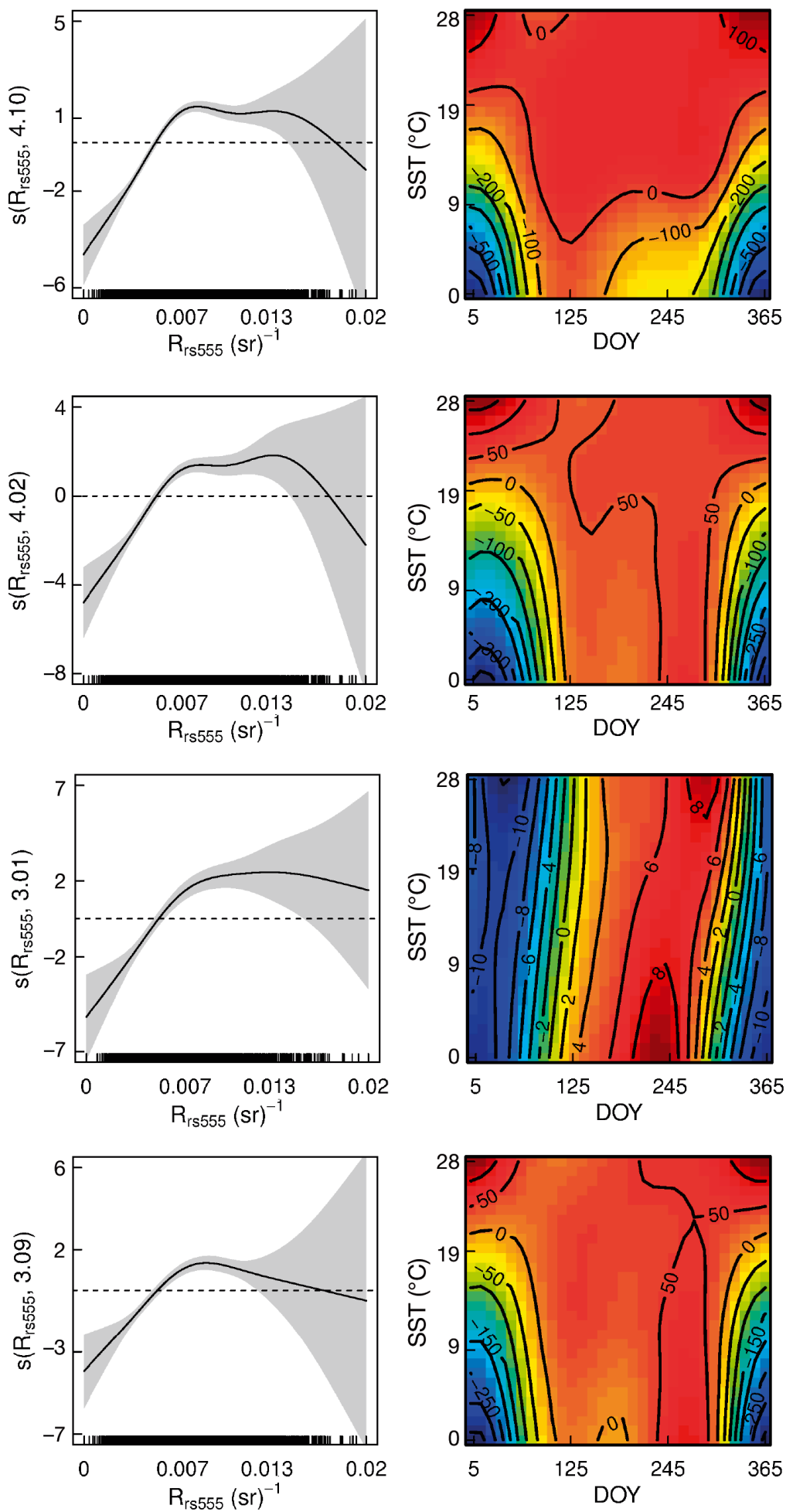

Fig. 3. Predictor variable response functions for generalized additive mixed models predicting the binomial response of (a) all, (b) adult male, (c) adult female, and (d) juvenile sand tigers Carcharias taurus within the coastal ocean study region. Black lines: smoothed curve of partial additive variable effect on probability of presence; grey shading: $95 \%$ confidence interval. Partial variable responses $>0$ are predictive of sand tiger occurrences, while partial variable responses $<0$ are predictive of absences. Short vertical lines (rug) on the $x$-axis of single variable plots represent the distribution of variable observations upon which the model's response was built. DOY: day of the year; SST: sea surface temperature; $\mathrm{R}_{\mathrm{rs} 555}$ : remote sensing reflectance 
a)

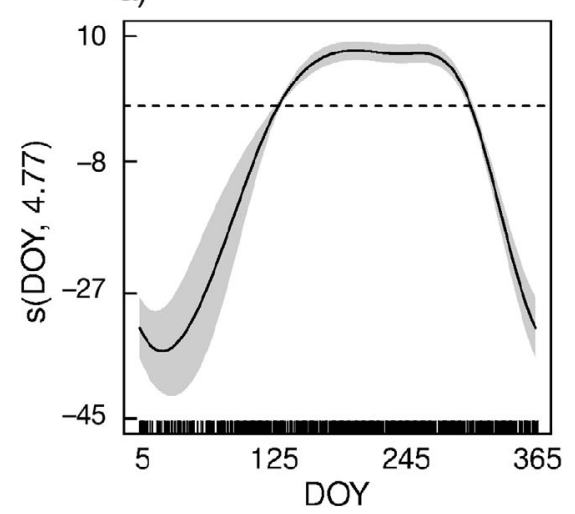

b)

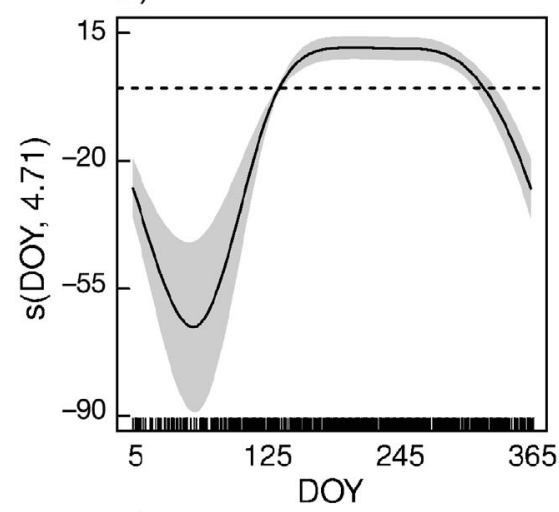

c)

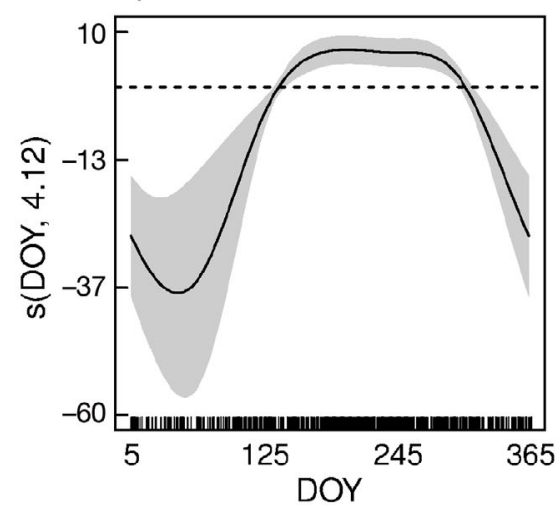

d)

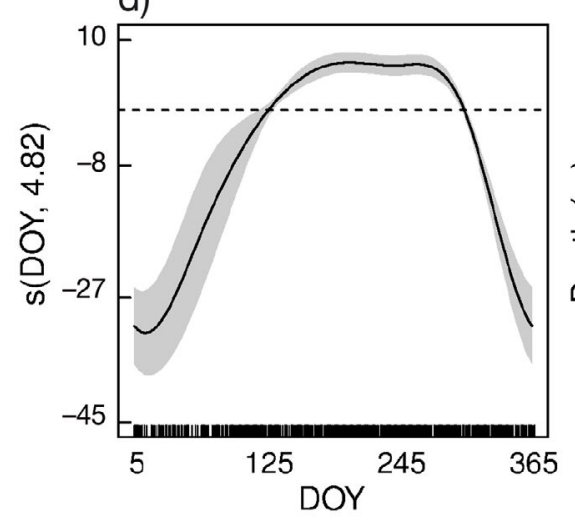

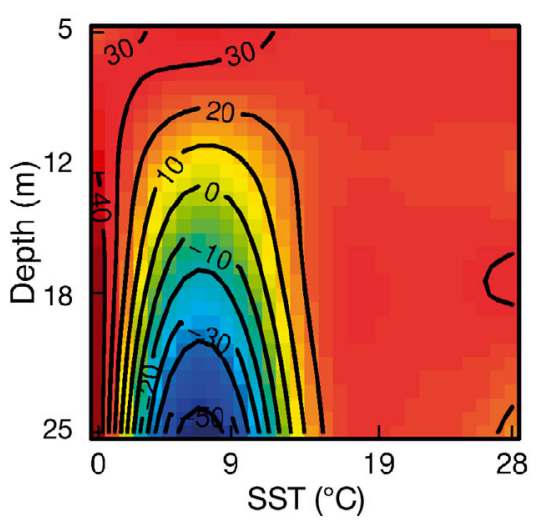
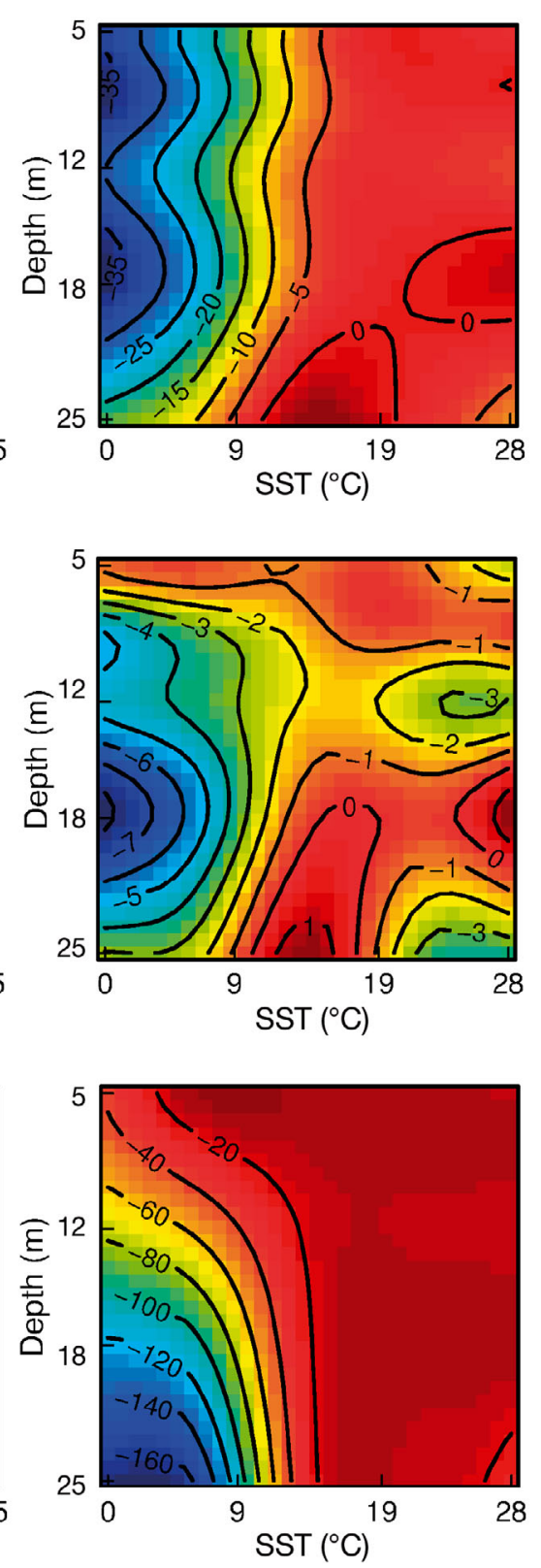

rence in the coastal ocean during the summer (Figs. S5c-S7c). Areas in the Delaware Bay with high probabilities of juvenile and adult male occurrence appeared similar, but adult females had lower occurrence predictions in August (Figs. S8c-S10c).

The fall migration of sand tigers out of the study regions occurred in October (DOY 275). All models predicted low probabilities of occurrence in Delaware Bay by early October (Fig. 6d, Figs. S8d-S10d). In the coastal ocean, occurrence extended further offshore than during the spring migration, and had higher probabilities of occurrence (Fig. 5d). Sand tigers using the waters further offshore during the fall were mainly the adult males and females (Figs. S5d-S7d).

The seasonal patterns of ecological habitat overlap by juvenile and adult (male and female) sand tigers can be observed in the presence/absence prediction maps based on the optimal threshold for each model (Supplemental Movie 5). In the coastal ocean, these maps and animations show the earlier arrival of juveniles in the spring, with juvenile occurrence potentially extending out to the edge of our model domain (Fig. 7a). In the summer, juveniles and adults occur together in the very nearshore waters along much of the coastline (Fig. $7 \mathrm{~b}$ ). During the fall migration south, the area of ocean occupied by both juveniles and adults extends further offshore again (Fig. 7c). Maps of ecological overlap for the Delaware Bay model show no clear patterns, because for most of the year, there is overlap between juveniles and adults throughout the entire bay at the spatial scale of our models.

\section{DISCUSSION}

Coastal marine species present difficult management and conservation issues because they often make largescale migrations, segregate by life

Fig. 4. As in Fig. 3, but for the Delaware Bay study region 

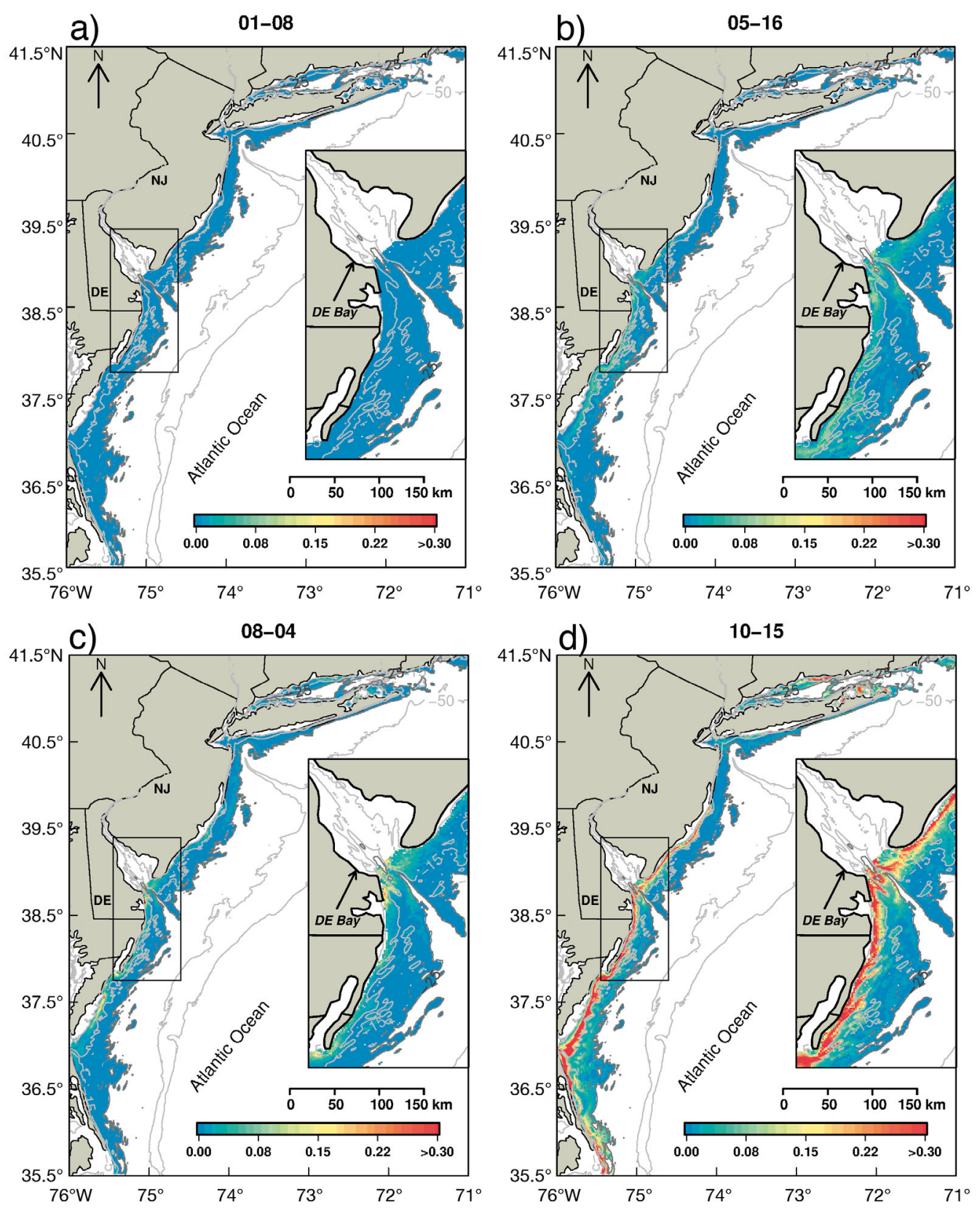

Fig. 5. Generalized additive mixed model probability of occurrence predictions (colors) for all sand tiger Carcharias taurus occurrence in the coastal ocean study region in (a) winter, (b) spring, (c) summer, and (d) fall using an 8 d climatology of sea surface temperature (SST) and remote sensing reflectance at $555 \mathrm{~nm}\left(\mathrm{R}_{\mathrm{rs} 555}\right)$ from the MODIS-aqua satellite record, day of year, and depth as predictor inputs. Inset map shows predictions within the approximate domain of acoustic receiver arrays, where model performance was cross validated. Predictions outside of the inset should be considered preliminary. Dates above each panel (mo-d) reflect the first day of each $8 \mathrm{~d}$ period for climatological data used for prediction

history stage, and are found in close proximity to humans where they are susceptible to various forms of exploitation that may fall under the jurisdiction of multiple entities (Speed et al. 2010). Dynamic habitat models allow managers to identify speciesspecific core habitats, thereby identifying areas of likely human interaction (Bonfil 1997, Speed et al. 2010, Zydelis et al. 2011, Teter et al. 2015). Our models use publicly available remotely sensed and static ocean properties to create predictive distribution maps for sand tigers. We also analyzed the differences in the timing and distribution of juveniles, adult males, and adult females in the Delaware Bay and western Mid-Atlantic coastal ocean. This geographical area is one of active concern for conservation efforts, as sand tigers have been found to con- 

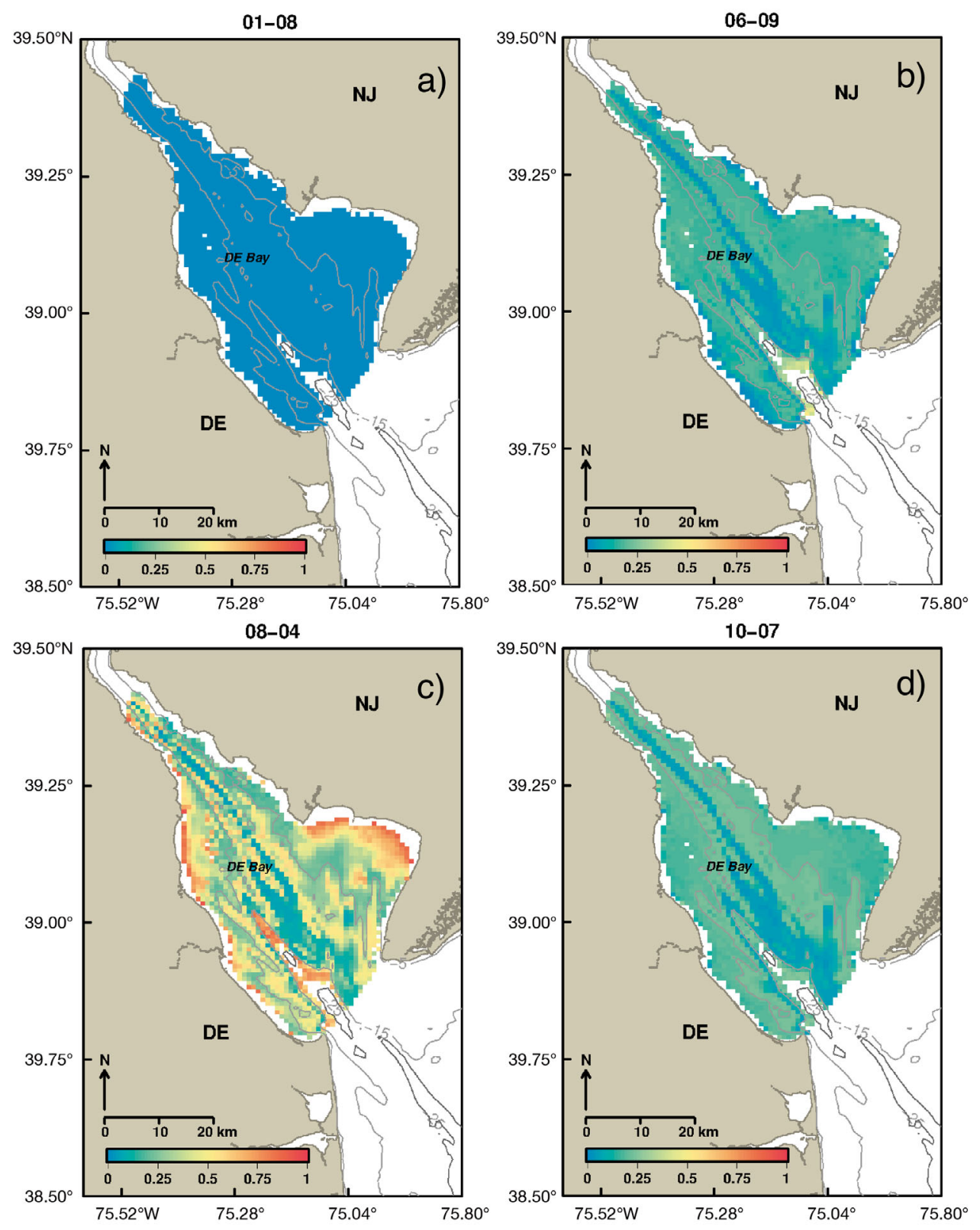

Fig. 6. Generalized additive mixed model probability of occurrence predictions (colors) for all sand tiger Carcharias taurus occurrence in the Delaware Bay study region in (a) winter, (b) spring, (c) summer, and (d) fall using an 8 d climatology of sea surface temperature (SST) from the MODIS aqua satellite record, day of year, and depth as predictor inputs. Dates above each panel (mo-d) reflect the first day of each $8 \mathrm{~d}$ period for climatological data used for prediction. Note the later arrival and earlier departure of sharks from the region compared to the coastal ocean (see Fig. 5)

sistently return to the Delaware Bay and MidAtlantic coastal ocean during their migrations on an annual basis (NOAA 2017).

\section{Migration timing and migratory corridors}

Results from our GAMMs support current hypotheses of sand tiger migration into and out of the Mid-
Atlantic coastal ocean and Delaware Bay study regions (Kneebone et al. 2014, Haulsee et al. 2015, 2016, Teter et al. 2015). These movements are highly seasonal, with juvenile sand tigers consistently arriving earlier than adult sharks into the Delaware Bay and coastal ocean, at times arriving almost a month earlier than adult sharks. In contrast, all sharks left the coastal ocean the same time every fall (early to mid-October). 

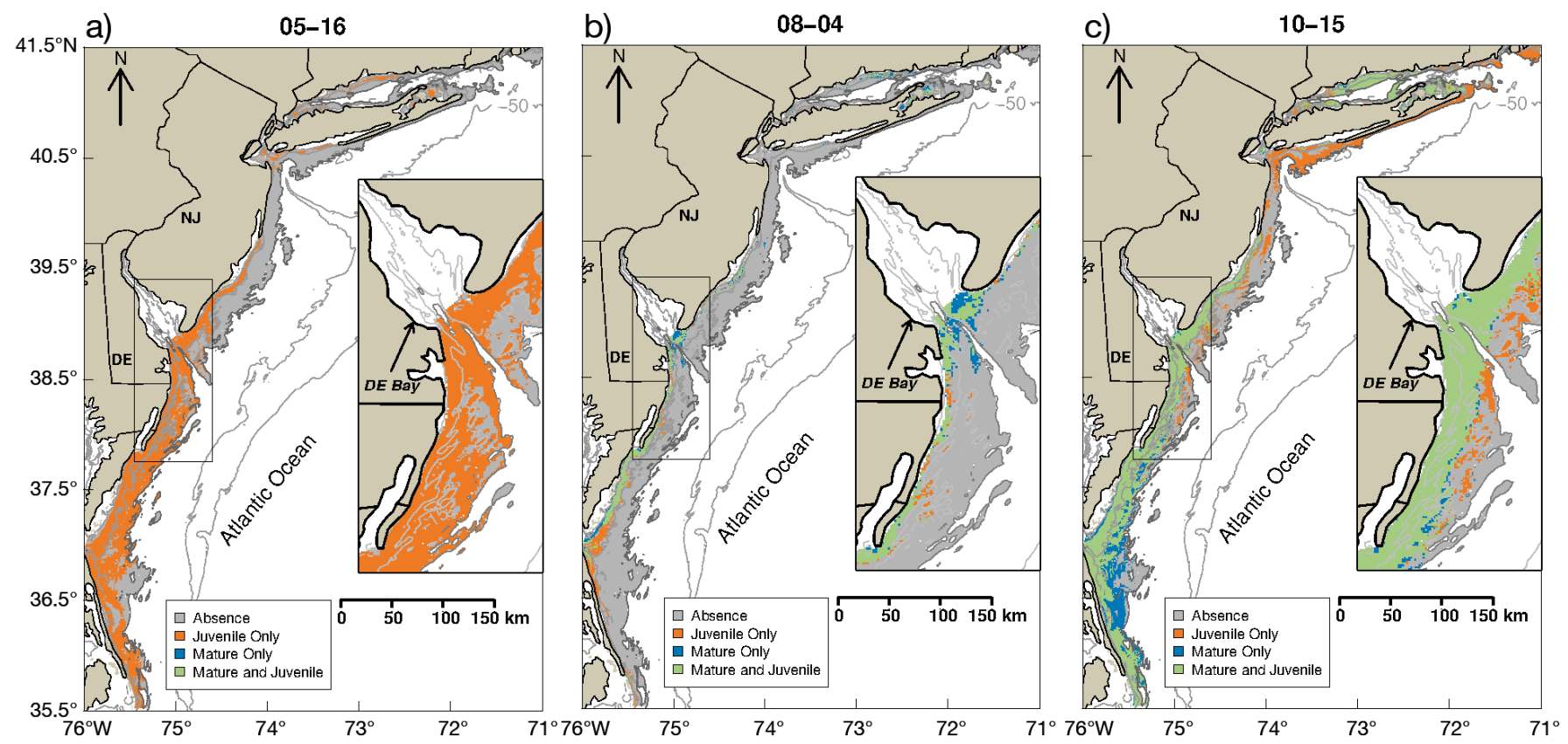

Fig. 7. Overlap of life history stages of sand tiger Carcharias taurus prevalence predicted by generalized additive mixed models in the coastal ocean study region in (a) spring, (b) summer, and (c) fall using an $8 \mathrm{~d}$ climatology of sea surface temperature (SST) and remote sensing reflectance at $555 \mathrm{~nm}$ (Rrs555) from the MODIS-aqua satellite record, day of year, and depth as a predictor inputs. Dates above each panel (mo-d) reflect the first day of each $8 \mathrm{~d}$ period for climatological data used for prediction

The gradual arrival and rapid departure of sand tigers into our study regions indicates that there are likely different forces driving these behaviors depending on the season. SST is included in all models and is likely a strong seasonal driver of occurrence. However, DOY is the most important predictor of occurrence in almost all models, indicating that there are seasonal environmental or behavioral drivers besides SST that may influence the timing of the migrations of sand tigers. Size segregation in the spring migration is likely a function of small juveniles migrating earlier than adults, to avoid interspecific competition. Adult sharks seem to be reacting to water temperature, moving north into the Mid-Atlantic coastal ocean only when surface waters warm to approximately $18^{\circ} \mathrm{C}$. In the fall, the abrupt departure of the juveniles and adults indicates that the migratory cue may be something much more acute. Kneebone et al. (2012) concluded that the rapid emigration of juvenile sand tiger sharks from the Plymouth-Kingston-Duxbury Bay in Massachusetts, USA, was related to both water temperature and day length, but that day length might be a much stronger signal, cueing the dispersal of sharks from the region because of the consistency in the timing of sand tiger emigration over their study. We observed a similar pattern in the rapid emigration of juveniles and adults from the Delaware Bay and coastal ocean, rep- resented by the steep slope of the density plots of sand tiger presence (Fig. 2). This indicates that this behavior may be engrained in the population in the Western North Atlantic or possibly related to the behavioral response of sand tigers and/or their prey resources to de-stratification of the water column or other acute changes in environmental variables along the coast. Teter et al. (2015) detected no sand tigers on acoustic receivers in the Delaware Bay at surface temperatures below $18^{\circ} \mathrm{C}$, providing evidence that this temperature is an important thermal threshold for the arrival and departure of sand tigers or for the prey resources they depend on in the Delaware Bay.

A second notable difference predicted by the GAMMs was the difference in the migratory corridors used by sand tigers during the spring and fall. In the spring, the sharks were generally predicted to remain in the very nearshore, shallow waters as they migrated from the southern extent of our study region, to the Delaware Bay and further north. In the fall, all sand tigers extended their predicted occurrence further offshore. This supports previous observations of sand tiger migrations during the fall recorded by pop-up satellite archival tags (PSATs). In a previous study, PSATs recorded adult males and females migrating south or east further offshore (but note that error around estimated PSAT locations was 
very large) and in deeper water (average depths 18$73 \mathrm{~m}$ ) than our model was able to predict due to the observation constraints of the acoustic array $(<25 \mathrm{~m}$ depth) (Teter et al. 2015). Future studies using satellite tags on sand tigers during their spring migration would help confirm the differences in migratory corridors predicted by our models.

Adult females are predicted to occur in higher densities further offshore than the other life history stages. This pattern reflects suggested sexual segregation in the migratory routes chosen by adult males and females in the fall, with adult females migrating further offshore than adult males, and potentially heading east to northeast after emigrating from the Delaware Bay (Teter et al. 2015, Haulsee et al. 2016). Our models are likely missing the offshore portion of female sand tigers due to model constraints, as Teter et al. (2015) showed that females (sub-adult or recently adult) likely migrate much further offshore in the fall.

Sexual segregation is common in sharks (Klimley 1987, Sims 2005, Mucientes et al. 2009), but the underlying reason for this behavior in sand tigers at this point is not known. Haulsee et al. (2016) reported that during their southern fall migration, adult males were not found in close proximity to adult females, indicating segregation in the population that did not exist during the summer months, likely due to differences in the timing and locations of the adult female migration route. Segregation of adults during fall migrations may be related to females avoiding mating, with adult females using deeper waters further offshore to limit interaction with males (Teter et al. 2015). Klimley (1987) speculated that sexual segregation in scalloped hammerheads Sphyrna lewini resulted from females moving offshore to avoid aggressive males. Another possible explanation for sexual segregation in sand tigers is that energy requirements differ among juveniles and adults of both sexes. The movement of adult females offshore in the fall may be a result of increased reproductive energy demands, whereby individuals are taking advantage of warmer and more productive Gulf Stream waters (Teter et al. 2015).

\section{Interpretation of predictor variables}

Sand tigers have been documented in ocean temperatures ranging from $9.8-26.9^{\circ} \mathrm{C}$ for juveniles at the northern extent of their range (Kneebone et al. 2014), and $13-26^{\circ} \mathrm{C}$ in the Delaware Bay and surrounding coastal waters (Teter et al. 2015), which corresponds to the SST range observed for all sharks in our study $\left(\sim 13-31^{\circ} \mathrm{C}\right)$. The interaction between DOY and SST included in all of the coastal ocean models allows the model to account for shifts in temperature preferences that may be related to sand tiger life history; however, due to the additive nature of a GAMM, these patterns are difficult to interpret in the response plots.

$\mathrm{R}_{\mathrm{r} 5555}$ was included in the coastal ocean models. To our knowledge, this is the first study to use ocean color reflectance as a dynamic environmental predictor of shark occurrence. $\mathrm{R}_{\mathrm{rs} 555}$ is bright green and is commonly used in algorithms calculating chlorophyll a concentrations in the ocean (O'Reilly et al. 1998). In the coastal ocean, phytoplankton blooms can increase ocean turbidity and coincide with elevated levels of colored dissolved organic matter (CDOM) (Vodacek et al. 1997). Previously, a study of sand tiger sharks in the Mid-Atlantic coastal ocean found that they were selecting for ocean waters with elevated levels of CDOM (Haulsee et al. 2015). Smale (2002) also observed a relationship between turbid waters and increased sand tiger occurrence in the coastal waters off South Africa. Often, turbidity is related to freshwater plumes exiting estuarine systems (Geiger et al. 2013), and may be an olfactory navigational cue for sand tigers migrating along the eastern coast of the USA (Montgomery \& Walker 2001, Haulsee et al. 2015). In addition, turbid waters may increase the stealth of a predatory shark stalking prey (Ebert 1991), allow conspecifics living in relatively close proximity to avoid potentially aggressive interactions (Chin et al. 2013), or simply attract aggregations of prey fish feeding on phytoplankton and zooplankton blooms.

Depth as a predictor variable is likely a proxy for other environmental conditions that are important to sand tigers. Globally, sand tigers are found around reefs, shipwrecks, or other forms of physical structure (Pollard et al. 1996, Smale 2002, Whitfield et al. 2011). In a soft-bottomed system like the Delaware Bay, rapid changes in depth along the edges of channels and sloughs may act as surrogates to physical structure for sand tigers. In addition, sand tigers were observed in waters with SSTs up to $\sim 31^{\circ} \mathrm{C}$ in the Delaware Bay; however, PSATs rarely recorded sand tigers in ambient sea water temperatures higher than $23^{\circ} \mathrm{C}$ (Teter et al. 2015), indicating that they may be choosing to spend time in the deeper channels of the bay to reduce energetic costs during times of rest, and moving to warmer and shallower waters only briefly to feed (Sims et al. 2006). This behavioral switch may explain our models predicting daily sand 
tiger occurrence in both shallow and deep areas of Delaware Bay, but observations on the scale of the individual are necessary to confirm this hypothesis.

\section{CONCLUSIONS}

While the extensive Delaware Bay and coastal ocean acoustic array used in this study covers a large spatial area and wide range of environmental conditions, there are limitations in our predictions based on the array design and temporal coverage. Due to changes in ocean conditions, the probability of acoustic transmitter detection likely fluctuated throughout the study. This likely resulted in an underestimation of the presences of sand tigers in the study. A more thorough range testing effort in future studies would allow us to estimate the probability of detection to include in model interpretation. Future studies should extend telemetry assets into deeper waters to locate the offshore extent of the sand tiger migratory corridor, either by mooring receivers further from the coast, using mobile telemetry platforms such as wave gliders or Slocum electric gliders (Oliver et al. 2013, Haulsee et al. 2015), or deploying additional PSATs on adult females (Teter et al. 2015). In addition, increased receiver coverage of the coastal ocean to the north and south of the Delaware Bay would improve our confidence in predictions within the full extent of the Mid-Atlantic study region. Similarly, an independent dataset of sand tiger occurrence from fishery bycatch records would be useful to validate our model predictions; however, this dataset is not available at the spatial and temporal resolution of our model at this time. Until sand tiger locations can be obtained throughout the broader spatial extent of our model predictions, predictions outside the extent of the receiver array and highlighted in Figs. $5 \& 6$ should be used with caution. Finally, data limitations on adult female behavior require interpretations of modeled adult female occurrence to be used with caution until future studies can obtain more observations of their behavior in the coastal ocean.

By coupling both remotely sensed and static environmental predictor variables with presence/absence records from a large-scale telemetry project, we created dynamic predictive species distribution models for sand tigers in Delaware Bay and the coastal ocean. These models incorporate species location records using acoustic telemetry, with freely available ocean surface properties. Our models allow us to create daily, near real-time forecasts of where sand tigers are likely to be in the Mid-Atlantic Bight, al- lowing managers to assess potential interactions between humans and these sharks. The MODIS Aqua satellite overpass schedule images the Mid-Atlantic every afternoon, allowing for a new model prediction of sand tiger occurrence to be created daily. Clouds interfere with satellite coverage, meaning that composite satellite images $(1,3$, or $8 \mathrm{~d})$ may be necessary inputs to increase spatial coverage of model predictions, depending on the management question.

Through our efforts, we developed sex and reproductive stage-specific models to capture habitat preferences and migratory behaviors related to segregation among sand tigers. As resource managers continue to develop and implement conservation strategies for this coastal apex predator, we believe our models outline features of sand tiger biogeography that are necessary for determining occupancy patterns in nearshore regions. Sand tiger populations are Critically Endangered (IUCN designation) in the Southwestern Atlantic and in eastern Australia, and applying this modeling technique in those regions may assist recovery efforts by providing more detail about habitat use and interactions with humans. Identifying areas of occupancy allows for dynamic and directed enforcement of fishing restrictions for protected species, and allows managers to seasonally and spatially restrict construction, dredging, shipping, or fishing activities from occurring in areas important for conservation. Identifying and predicting habitats where sand tigers or other coastal sharks of interest likely occur is a powerful tool for identifying essential habitat and potential threats to the recovery of a population.

Acknowledgements. We thank 3 anonymous reviewers whose comments and critiques greatly improved this manuscript. This work was supported by the Lenfest Ocean Program 00026773. We also thank M. Cimino, C. Goodrich, and J. Gradone for their helpful insight into data analysis and interpretation, and M. Shatley for his assistance processing the remote sensing data used in the analysis.

\section{LITERATURE CITED}

Aarts G, MacKenzie M, McConnell B, Fedak M, Matthiopoulos J (2008) Estimating space use and habitat preference from wildlife telemetry data. Ecography 31:140-160

Adams GD, Flores D, Flores OG, Aarestrup K, Svendsen JC (2016) Spatial ecology of blue shark and shortfin mako in Southern Peru: local abundance, habitat preferences and implications for conservation. Endang Species Res 31: 19-32

Ahonen H, Harcourt RG, Stow AJ (2009) Nuclear and mitochondrial DNA reveals isolation of imperilled grey nurse shark populations (Carcharias taurus). Mol Ecol 18: 4409-4421 
Bansemer CS, Bennett MB (2011) Sex-and maturity-based differences in movement and migration patterns of grey nurse shark, Carcharias taurus, along the eastern coast of Australia. Mar Freshw Res 62:596-606

Bonfil R (1997) Status of shark resources in the southern Gulf of Mexico and Caribbean: implications for management. Fish Res 29:101-117

Bornatowski H, Navia AF, Braga RR, Abilhoa V, Corrêa MFM (2014) Ecological importance of sharks and rays in a structural foodweb analysis in southern brazil. ICES J Mar Sci 71:1586-1592

Breece MW, Fox DA, Dunton KJ, Frisk MG, Jordaan A, Oliver MJ (2016) Dynamic seascapes predict the marine occurrence of an endangered species: Atlantic sturgeon Acipenser oxyrinchus oxyrinchus. Methods Ecol Evol 7: 725-733

Burkholder DA, Heithaus MR, Fourqurean JW, Wirsing A, Dill LM (2013) Patterns of top down control in a seagrass ecosystem: Could a roving apex predator induce a behaviour-mediated trophic cascade? J Anim Ecol 82: 1192-1202

Carlson JK, McCandless CT, Cortés E, Grubbs RD, Andrews KI, MacNeil M, Musick JA (2009) Update on the status of the sand tiger shark, Carcharias taurus in the Northwest Atlantic Ocean. Tech Memo NMFS-SEFSC-585. NOAA, National Marine Fisheries Service, Panama City, FL

Chiaramonte G, Domingo A, Soto J (2007) Carcharias taurus (Southwest Atlantic subpopulation). The IUCN Red List of Threatened Species 2007: e.T63163A12625032

Chin A, Tobin AJ, Heupel MR, Simpfendorfer CA (2013) Population structure and residency patterns of the blacktip reef shark Carcharhinus melanopterus in turbid coastal environments. J Fish Biol 82:1192-1210

Compagno LJV (2001) Sharks of the world: an annotated and illustrated catalogue of shark species known to date. FAO, Rome

₹ Dicken ML, Booth AJ, Smale MJ, Cliff G (2007) Spatial and seasonal distribution patterns of juvenile and adult raggedtooth sharks (Carcharias taurus) tagged off the east coast of South Africa. Mar Freshw Res 58:127-134

Donaldson MR, Hinch SG, Suski CD, Fisk AT, Heupel MR, Cooke SJ (2014) Making connections in aquatic ecosystems with acoustic telemetry monitoring. Front Ecol Environ 12:565-573

Ebert DA (1991) Observations on the predatory behaviour of the sevengill shark Notorynchus cepedianus. S Afr J Mar Sci 11:455-465

Freeman EG (2008) PresenceAbsence: an R package for presence-absence model analysis. J Stat Softw 23:1-31

* García VB, Lucifora LO, Myers RA (2008) The importance of habitat and life history to extinction risk in sharks, skates, rays and chimaeras. Proc R Soc B 275:83-89

* Geiger EF, Grossi MD, Trembanis AC, Kohut JT, Oliver MJ (2013) Satellite-derived coastal ocean and estuarine salinity in the Mid-Atlantic. Cont Shelf Res 63:S235-S242

Gilmore RG, Dodrill JW, Linley PA (1983) Reproduction and embryonic development of the sand tiger shark, Odontaspis taurus (Rafinesque). Fish Bull 81:201-225

Hastie TJ, Tibshirani RJ (1990) Generalized additive models. Chapman and Hall, London

Haulsee DE, Breece MW, Miller DC, Wetherbee BM, Fox DA, Oliver MJ (2015) Habitat selection of a coastal shark species estimated from an autonomous underwater vehicle. Mar Ecol Prog Ser 528:277-288

*Haulsee DE, Fox DA, Breece MW, Brown LM, Kneebone J,
Skomal GB, Oliver MJ (2016) Social network analysis reveals potential fission-fusion behavior in a shark. Sci Rep 6:34087

*Hazen EL, Palacios DM, Forney KA, Howell EA and others (2017) Whalewatch: a dynamic management tool for predicting blue whale density in the California Current. J Appl Ecol 54:1415-1428

* Heupel MR, Semmens JM, Hobday AJ (2006) Automated acoustic tracking of aquatic animals: scales, design and deployment of listening station arrays. Mar Freshw Res 57:1-13

*Hussey NE, Kessel ST, Aarestrup K, Cooke SJ and others (2015) Aquatic animal telemetry: a panoramic window into the underwater world. Science 348:1255642

Jackson GD (2011) The development of the Pacific Ocean shelf tracking project within the decade long census of marine life. PLOS ONE 6:e18999

Kessel ST, Cooke SJ, Heupel MR, Hussey NE, Simpfendorfer CA, Vagle S, Fisk AT (2014) A review of detection range testing in aquatic passive acoustic telemetry studies. Rev Fish Biol Fish 24:199-218

Kilfoil JP, Wetherbee BM, Carlson JK, Fox DA (2017) Targeted catch-and-release of prohibited sharks: sand tigers in coastal Delaware waters. Fisheries 42:281-287

* Kinney MJ, Simpfendorfer CA (2009) Reassessing the value of nursery areas to shark conservation and management. Conserv Lett 2:53-60

Klimley AP (1987) The determinants of sexual segregation in the scalloped hammerhead shark, Sphyrna lewini. Environ Biol Fishes 18:27-40

Kneebone J, Chisholm J, Skomal GB (2012) Seasonal residency, habitat use, and site fidelity of juvenile sand tiger sharks Carcharias taurus in a Massachusetts estuary. Mar Ecol Prog Ser 471:165-181

Kneebone J, Chisholm J, Bernal D, Skomal G (2013) The physiological effects of capture stress, recovery, and postrelease survivorship of juvenile sand tigers (Carcharias taurus) caught on rod and reel. Fish Res 147:103-114

Kneebone J, Chisholm J, Skomal G (2014) Movement patterns of juvenile sand tigers (Carcharias taurus) along the east coast of the USA. Mar Biol 161:1149-1163

Lin X, Zhang D (1999) Inference in generalized additive mixed models using smoothing splines. J R Stat Soc Series B Stat Methodol 61:381-400

KLucifora LO, Menni RC, Escalante AH (2002) Reproductive ecology and abundance of the sand tiger shark, Carcharias taurus, from the southwestern Atlantic. ICES J Mar Sci 59:553-561

*Manderson JP (2016) Seascapes are not landscapes: an analysis performed using Bernhard Riemann's rules. ICES J Mar Sci 73:1831-1838

*Manderson JP, Stehlik LL, Pessutti J, Rosendale J, Phelan B (2014) Residence time and habitat duration for predators in a small mid-Atlantic estuary. Fish Bull 112: 144-159

*Marra G, Wood SN (2011) Practical variable selection for generalized additive models. Comput Stat Data Anal 55: 2372-2387

Montgomery JC, Walker MM (2001) Orientation and navigation in elasmobranchs: which way forward? Environ Biol Fishes 60:109-116

Mucientes GR, Queiroz N, Sousa LL, Tarroso P, Sims DW (2009) Sexual segregation of pelagic sharks and the potential threat from fisheries. Biol Lett 5:156-159

Musick JA, Burgess G, Cailliet G, Camhi M, Fordham S 
(2000) Management of sharks and their relatives (Elasmobranchii). Fisheries 25:9-13

Myers RA, Worm B (2003) Rapid worldwide depletion of predatory fish communities. Nature 423:280-283

NOAA (2017) Atlantic highly migratory species; essential fish habitat. US Off Fed Reg 82:42329-42337

O'Reilly JE, Maritorena S, Mitchell BG, Siegel DA and others (1998) Ocean color chlorophyll algorithms for SeaWiFS. J Geophys Res 103:24937-24953

Oliver MJ, Breece MW, Fox DA, Haulsee DE, Kohut JT, Manderson J, Savoy T (2013) Shrinking the haystack: using an AUV in an integrated ocean observatory to map Atlantic sturgeon in the coastal ocean. Fisheries 38: 210-216

Oliver MJ, Breece MW, Haulsee DE, Cimino MA, Kohut JT, Aragon D, Fox DA (2017) Factors affecting detection efficiency of mobile telemetry Slocum gliders. Anim Biotelem 5:14

Pollard D, Smith A (2009) Carcharias taurus. The IUCN Red List of Threatened Species 2009:e.T3854A10132481

Pollard DA, Lincoln Smith MP, Smith AK (1996) The biology and conservation status of the grey nurse shark (Carcharias taurus Rafinesque 1810) in New South Wales, Australia. Aquat Conserv 6:1-20

Pollard D, Gordon I, Williams S, Flaherty A, McAuley R (2003) Carcharias taurus (East coast of Australia subpopulation). The IUCN Red List of Threatened Species 2003: e.T44070A10854830

Prabhakaran S (2016) InformationValue: performance analysis and companion functions for binary classification models. R package version 1.2.3. https://CRAN.Rproject.org/package=InformationValue

R Core Team (2017) R: a language and environment for statistical computing. R Foundation for Statistical Computing, Vienna

Scales KL, Hazen EL, Jacox MG, Edwards CA, Boustany AM, Oliver MJ, Bograd SJ (2017) Scale of inference: on the sensitivity of habitat models for wide-ranging marine predators to the resolution of environmental data. Ecography 40:210-220

Siegel DA, Maritorena S, Nelson NB, Behrenfeld MJ, McClain CR (2005) Colored dissolved organic matter and its influence on the satellite-based characterization of the ocean biosphere. Geophys Res Lett 32:L20605

Simpfendorfer CA, Freitas GG, Wiley TR, Heupel MR (2005) Distribution and habitat partitioning of immature bull sharks (Carcharhinus leucas) in a Southwest Florida estuary. Estuaries 28:78-85

Sims DW (2005) Differences in habitat selection and reproductive strategies of male and female sharks. In: Ruckstuhl KE, Neuhaus P (eds) Sexual segregation in verte-

Editorial responsibility: Peter Corkeron, Woods Hole, Massachusetts, USA brates: ecology of the two sexes. Cambridge University Press, Cambridge, p 127-147

Sims DW, Wearmouth VJ, Southall EJ, Hill JM and others (2006) Hunt warm, rest cool: bioenergetic strategy underlying diel vertical migration of a benthic shark. J Anim Ecol 75:176-190

Smale MJ (2002) Occurrence of Carcharias taurus in nursery areas of the Eastern and Western Cape, South Africa. Mar Freshw Res 53:551-556

Speed CW, Field IC, Meekan MG, Bradshaw CJA (2010) Complexities of coastal shark movements and their implications for management. Mar Ecol Prog Ser 408: 275-293

KStevens JD, Bonfil R, Dulvy NK, Walker PA (2000) The effects of fishing on sharks, rays, and chimaeras (chondrichthyans), and the implications for marine ecosystems. ICES J Mar Sci 57:476-494

Teter SM, Wetherbee BM, Fox DA, Lam CH, Kiefer DA, Shivji M (2015) Migratory patterns and habitat use of the sand tiger shark (Carcharias taurus) in the western North Atlantic. Mar Freshw Res 66:158-169

* Topelko KN, Dearden P (2005) The shark watching industry and its potential contribution to shark conservation. J Ecotour 4:108-128

* Vodacek A, Blough NV, Degrandpre MD, Nelson RK (1997) Seasonal variation of CDOM and DOC in the Middle Atlantic Bight: terrestrial inputs and photooxidation. Limnol Oceanogr 42:674-686

Wegmann M, Leutner B, Dech S (2016) Remote sensing and GIS for ecologists: using open source software. Pelagic Publishing, Exeter

Whitfield PE, Muñoz RC, Buckell CA, Heesemann LM (2011) Fish and habitat community assessments on North Carolina shipwrecks: potential sites for detecting climate change in the Graveyard of the Atlantic. Marine Sanctuaries Conservation Series. Office of National Marine Sanctuaries, Silver Spring, MD

*Wood SN (2004) Stable and efficient multiple smoothing parameter estimation for generalized additive models. J Am Stat Assoc 99:673-686

Wood S (2006) Generalized additive models: an introduction with R. Chapman \& Hall/CRC, Boca Raton, FL

Wood S, Scheipl F (2016) gamm4: generalized additive mixed models using 'mgcv' and 'lme4'. R package version 0.2-5. https://CRAN.R-project.org/package=gamm4

Whood SN, Scheipl F, Faraway JJ (2013) Straightforward intermediate rank tensor product smoothing in mixed models. Stat Comput 23:341-360

Zydelis R, Lewison RL, Shaffer SA, Moore JE and others (2011) Dynamic habitat models: using telemetry data to project fisheries bycatch. Proc R Soc B 278:3191-3200

Submitted: September 13, 2017; Accepted: April 4, 2018

Proofs received from author(s): June 3, 2018 